\title{
Long-acting porcine sequence ACTH in the diagnosis of adrenal insufficiency: a cost-effective alternative to the ACTH $_{1-24}$ test
}

\author{
Warrick J Inder
}

Department of Diabetes and Endocrinology, Princess Alexandra Hospital, and PA-Southside Clinical Unit, Faculty of Medicine, The University of Queensland, Brisbane, Queensland, Australia

Correspondence should be addressed to W J Inder

Email

Warrick.Inder@health.qld. gov.au

\begin{abstract}
While the $\mathrm{ACTH}_{1-24}$ test has some well-documented shortcomings, it is the most widely used test to diagnose primary and secondary adrenal insufficiency. However, this synthetic ACTH preparation is not readily available in some countries. Research from India has demonstrated that using a long-acting porcine sequence ACTH has similar diagnostic performance to $\mathrm{ACTH}_{1-24}$ at around $25 \%$ of the cost. This may allow access to a robust test for adrenal insufficiency to developing countries and potentially allow thousands of patients to be identified and appropriately treated.
\end{abstract}

The $\mathrm{ACTH}_{1-24}$ test, also known as the short Synacthen ${ }^{\circledR}$ test or the Cosyntropin test depending on your country of origin, was first used as a test of hypothalamic-pituitary adrenal axis function in the 1960s (1). Across the ensuing decades, debate has raged about many issues such as whether it is an accurate enough measure for secondary adrenal insufficiency (2), what dose of $\mathrm{ACTH}_{1-24}$ should be used (2), optimal timing of blood samples (3), the effect of different cortisol assays on diagnostic cut-offs $(4,5)$ and thresholds for basal cortisol which might make such a test unnecessary (6). As time and further research have progressed, we now have answers to most of these questions, providing endocrinologists with a 'reasonably' clear picture of the strengths and limitations of the $\mathrm{ACTH}_{1-24}$ test. However one issue which I suspect most endocrinologists practising in developed countries have never needed to consider is the cost and availability of $\mathrm{ACTH}_{1-24}$.

The recently published paper by Nair et al. from Thiruvananthapuram, India reports the results of a comparative study between $\mathrm{ACTH}_{1-24}$ and long-acting porcine sequence ACTH known as Acton Prolongatum ${ }^{\circledR}$ in the diagnosis of adrenal insufficiency (7). $\mathrm{ACTH}_{1-24}$ is not marketed in India, and while the authors managed to access this, the cost was 14 times higher per dose of Synacthen ${ }^{\circledR}$ compared to Acton Prolongatum ${ }^{\circledR}$. They cite several other studies, also from India, where the cortisol response to Acton Prolongatum ${ }^{\circledR}$ has been reported. For example, Gundguruthy et al. examined the cortisol response in healthy volunteers and patients with adrenal insufficiency (8), while Wagmode et al. examined healthy volunteers but also used the $\mathrm{ACTH}_{1-24}$ test as a comparator (9).

Thus, there is a growing body of literature from India which attests to the safety and efficacy of Acton Prolongatum ${ }^{\circledR}$ as an alternative ACTH stimulation test with Nair et al. being the first to undertake a comprehensive comparative study in adults with suspected adrenal insufficiency and publish their data in an international Endocrine journal (7). Their results demonstrate that 30 IU of Acton Prolongatum ${ }^{\circledR}$ may be a slightly more potent
Published by Bioscientifica Ltd. 
stimulus to cortisol secretion than $250 \mu \mathrm{g}$ of $\mathrm{ACTH}_{1-24}$ at $60 \mathrm{~min}$, though this failed to reach statistical significance $(P=0.072)$. By receiver-operating characteristic (ROC) curve analysis, the diagnostic performance of Acton Prolongatum ${ }^{\circledR}$ was optimal using the 120 -min cortisol concentration. Compared to the $\mathrm{ACTH}_{1-24}$ test, Acton Prolongatum ${ }^{\circledR}$ showed a sensitivity of $100 \%$ in diagnosing adrenal insufficiency with specificity between 84 and $88 \%$ depending on the cortisol cut-off used. No adverse effects were noted with the administration of either Synacthen ${ }^{\circledR}$ or Acton Prolongatum ${ }^{\circledR}$. However, the administration of a porcine protein potentially increases the likelihood of antibody formation, the clinical relevance of which remains to be determined.

The authors do not claim that the use of Acton Prolongatum ${ }^{\circledR}$ is a better or more accurate test for adrenal insufficiency than $\mathrm{ACTH}_{1-24}$. Their results suggest that the use of a different ACTH preparation, when combined with time- and cortisol assay-specific cut-offs provides a similar degree of diagnostic performance. The main differentiating feature is the cost. As noted earlier, the cost per dose of Acton Prolongatum ${ }^{\circledR} 30$ IU was 14 times less than Synacthen ${ }^{\circledR} 250 \mu \mathrm{g}$ in India. When translated to the cost of the entire test, the authors' calculated savings were $75 \%$ - \$US44 for $\mathrm{ACTH}_{1-24}$ versus $\$$ US11 for Acton Prolongatum ${ }^{\circledR}$. Given the results as presented, the 60 -min cortisol sample during the Acton Prolongatum ${ }^{\circledR}$ test appears to be redundant, meaning that further savings are possible with just a baseline and 120-min cortisol. This would bring the cost down to less than \$US10 per stimulation test.

Using Acton Prolongatum ${ }^{\circledR}$ is likely to have essentially the same issues as $\mathrm{ACTH}_{1-24}$ in terms of diagnostic accuracy and error. There will be patients with secondary adrenal insufficiency who pass the test. The dose used in the study by Nair et al. was different to previous Indian studies (which used $25 \mathrm{IU}$ ) and calculated simply because at a dose of $30 \mathrm{IU}$, ten stimulation tests were possible from a $300 \mathrm{IU}$ in $5 \mathrm{~mL}$ vial. One could argue that using $25 \mathrm{IU}$ as in the study by Gundgurthi et al. (8) (therefore 12 tests from a $300 \mathrm{IU}$ vial), could improve the financial bottom line even further. Gundgurthi et al. reported that all participants in their validation cohort who were healthy volunteers, or had either diabetes mellitus or primary hypothyroidism, exceeded a cortisol of $20 \mu \mathrm{g} / \mathrm{dL}$ at $60 \mathrm{~min}$ (Beckman Coulter RIA) (8). Given that the cortisol would have been higher at $120 \mathrm{~min}$, a dose of $25 \mathrm{IU}$ probably results in a similar degree of adrenal stimulation as $30 \mathrm{IU}$. However, $30 \mathrm{IU}$ is an even $0.5 \mathrm{~mL}$ volume, whereas $25 \mathrm{IU}$ is $0.42 \mathrm{~mL}$. Therefore on balance, standardising the Acton
Prolongatum ${ }^{\circledR}$ dose to $30 \mathrm{IU}$ in $0.5 \mathrm{~mL}$ with cortisol samples at 0 and 120 min would appear to make a lot of sense in terms of ease in administration.

Any diagnostic test measuring cortisol must take into account the assay used. The newer cortisol II standard as used by Nair et al. has been shown to read cortisol concentrations considerably lower than other immunoassays, with cutoffs for the $\mathrm{ACTH}_{1-24}$ test suggested between 350 and 400 $\mathrm{nmol} / \mathrm{L}(12.7-14.5 \mu \mathrm{g} / \mathrm{dL})$ rather than the traditional 500 $\mathrm{nmol} / \mathrm{L}(18 \mu \mathrm{g} / \mathrm{dL})(5,10)$. There are an increasing number of commercial laboratories now moving to routine use of liquid chromatography-dual mass spectrometry (LC-MS/MS) to measure cortisol and other steroid hormones (5). Therefore it is imperative that laboratories establish a reference range for basal and stimulated cortisol consistent with the assay they are using.

In summary, the study by Nair et al. presents a diagnostic test for adrenal insufficiency in the developing world whose safety and accuracy are similar to $\mathrm{ACTH}_{1-24}$, but at a fraction of the cost. This has the potential for thousands of people being offered a test that would have been previously unavailable, leading to the commencement of life-saving glucocorticoid replacement therapy.

\section{Declaration of interest}

The author declares that there is no conflict of interest that could be perceived as prejudicing the impartiality of this commentary.

\section{Funding}

This commentary did not receive any specific grant from any funding agency in the public, commercial or not-for-profit sector.

\section{References}

1 Wood JB, Frankland AW, James VH \& Landon J. A rapid test of adrenocortical function. Lancet 19651 243-245. (https://doi. org/10.1016/s0140-6736(65)91526-6)

2 Ospina NS, Al Nofal A, Bancos I, Javed A, Benkhadra K, Kapoor E, Lteif AN, Natt N \& Murad MH. ACTH stimulation tests for the diagnosis of adrenal insufficiency: systematic review and metaanalysis. Journal of Clinical Endocrinology and Metabolism 2016101 427-434. (https://doi.org/10.1210/jc.2015-1700)

3 Chitale A, Musonda P, McGregor AM \& Dhatariya KK. Determining the utility of the 60 min cortisol measurement in the short synacthen test. Clinical Endocrinology 201379 14-19. (https://doi. org/10.1111/j.1365-2265.2012.04478.x)

4 El-Farhan N, Pickett A, Ducroq D, Bailey C, Mitchem K, Morgan N, Armston A, Jones L, Evans C \& Rees DA. Method-specific serum cortisol responses to the adrenocorticotrophin test: comparison of gas chromatography-mass spectrometry and five automated immunoassays. Clinical Endocrinology 201378 673-680. (https://doi. org/10.1111/cen.12039)

5 Javorsky B, Carroll T, Algeciras-Schimnich A, Singh R, ColonFranco J \& Findling JW. New cortisol threshold for diagnosis of 
adrenal insufficiency after cosyntropin stimulation testing using the Elecsys cortisol II, access cortisol and LC-MS/MS assays. Journal of the Endocrine Society 20193 (Supplement) SAT-390 3. (https://doi. org/10.1210/js.2019-SAT-390)

6 Mackenzie SD, Gifford RM, Boyle LD, Crane MS, Strachan MWJ \& Gibb FW. Validated criteria for the interpretation of a single measurement of serum cortisol in the investigation of suspected adrenal insufficiency. Clinical Endocrinology 201991 608-615. (https://doi.org/10.1111/cen.14071)

7 Nair A, Jayakumari C, George GS, Jabbar PK, Das DV, Jessy SJ \& Anish TS. Long acting porcine sequence ACTH in the diagnosis of adrenal insufficiency. European Journal of Endocrinology 2019181 639-645. (https://doi.org/10.1530/EJE-19-0558)
8 Gundgurthi A, Garg MK, Dutta MK \& Pakhetra R. Intramuscular ACTH stimulation test for assessment of adrenal function. Journal of the Association of Physicians of India 201361 320-324.

9 Wagmode NB, Mathew V, Bantwal G, Ayyar V, George B, Patanjali CP \& Michael J. It is time to carpe diem with porcine ACTH - a comparison of porcine sequence corticotropin to tetracosactide hexaacetate in testing the hypothalamic pituitary adrenal axis in healthy individuals. Indian Journal of Endocrinology and Metabolism 201822 636-640. (https://doi.org/10.4103/ijem.IJEM_114_18)

10 Kline GA, Buse J \& Krause RD. Clinical implications for biochemical diagnostic thresholds of adrenal sufficiency using a highly specific cortisol immunoassay. Clinical Biochemistry 201750 475-480. (https://doi.org/10.1016/j.clinbiochem.2017.02.008)

Received 13 November 2019

Accepted 21 November 2019 